\title{
The Boy Who Grew a New Brain: Understanding this Miracle from a Neuro-Quantum Perspective
}

\begin{abstract}
J. Shashi Kiran Reddy ${ }^{1}$, Contzen Pereira ${ }^{2 *}$
ABSTRACT

In this paper, we present a case of a boy - Noah Wall, who till today surprises the world of neuroscience with his will to grow his brain and survive. The case presented in this study sets a stepping stone in understanding the advent of the will to make a choice, from a neuro-quantum mechanics interpretation. We propose that besides our internal states of choices (neurogenesis, neuroplasticity, cell differentiation, etc.) we also relate with external states of choices (love, compassion, empathy, emotions, etc.) that contributes to its emergence. Quantum uncertainty seems to support the existence of a fundamental property based on which the universe functions; which means that even the nothing of free space has a small chance of containing something. Outcomes are not determined by prior or random events but by consciousness that gives rise to these outcomes. This provides us a lead into understanding the existence of the will and the origin of choice when we look deeper into the realms of the implausible interpretations of quantum mechanics. Free will is the ability for the mind to choose between possible outcomes. Willful power is therefore not only a psychological intervention but also a biological and quantum intervention, where we have the capacity to make choices about what direction we will take, making a change to the systematic functioning of our body.
\end{abstract}

Key Words: Free Will, Choice, Hydrocephalus, Spina Bifida, Neuro-Quantum Mechanics, Consciousness, Quantum Uncertainty, Noah

\section{Introduction}

Man is a masterpiece of creation if for no other reason than that, all the weight of evidence for determinism notwithstanding, he believes he has free will. (Lichtenberg 1789).

In our life, there is hardly a minute where we don't make a choice; be it conscious or unconscious (Finkelstein, 1999; Tversky and Kahneman, 1981). Free will, on the other hand, is a conscious choice of how we act and is usually paraded for a strong reason (Holton, 2006; Strle, 2014; Klemm, 2010; Morris, 2009). According to psychology, a choice is an outcome of a decisionmaking process and is made to satisfy our five basic needs: survival, love and belonging, power, freedom, and fun (Beresford and Sloper, 2008;
Glasser, 1998). But, on the other hand, neuroscience postulates that we actually don't make a choice nor do we have a will. This is because, as per neuroscience, choice and will happen in the subconscious and forms even before it appears in one's conscious awareness. Though one can quantify this phenomenon by means of a physical parameter such as the readiness potential (RP) or Bereitschaftspotential (BP) or pre-motor potential, this alone cannot be used as an absolute proof to deny the existence of the will (Kornhuber and Deecke, 1965; Libet, 1993; Peters et al., 2017). Functionally, the readiness potential is a measure of activity of the motor cortex and supplementary motor area leading to voluntary muscle movement; while exhibiting the will to make a choice 
to move. This has been measured and quantified in several neuroscientific studies (Baker et al., 2011; Zschorlich and Köhling, 2013; Lattari et al., 2014). Based on these findings, one can say that both the choice and the will to make a specific choice seems to have pre-designated already in the prefrontal cortex and frontoparietal cortical areas of the brain. In general, activity in these areas of the brain is associated with 'higher' brain functions essential for memory and problem solving (Domenech and Koechlin, 2015; Coutlee and Huettel, 2012). Some of the experiments in neuroscience have also shown the possibility to express our will in various degrees (though happens not in absolute freedom), during the initiation of our movements and actions. According to them, one can make efforts to increase one's degree of freedom or degree of free will through self-improvement, and at the same time, can possibly lose because of selfmismanagement (Deecke, 2012; Lavazza, 2016).

In an earlier paper, one of the present authors made an attempt to propose that children in cases of hydranencephaly are conscious from a quantum-mind interpretation (Pereira, 2016). This hypothesis challenges many of those who consider these individuals to demonstrate behaviors that are termed 'vegetative' or unconscious reflexes; despite the fact that they respond to their surroundings in the form of emotional and environment-related events. In this paper, we present a similar but unique case. Unique in a way, because, here an individual with a hydrocephalus condition, somehow seem to have exhibited his will to make a choice to regress back to be normal. Re-growing a brain in a rather unique format, as in the present case (details of which we presented in the following section), is not yet known in the field of neuroscience. To explain such a unique phenomenon, we propose that, this is possible only through the support of the will and its power (that leads to the advent of an inherent choice to make such a reversal possible). This case definitely challenges the actuality and the power of the will that manifests in the occurrence of choice and thereby guides us to posit these concepts from a quantum mechanics interpretation.

In addition, some neuroscientists and child psychologists also claim that consciousness is not present in children till the age of three (from the time of their conception). This is because, they believe that, this is the time during which a child's brain is known to undergo an impressive amount of change (Largercrantz and Changeux, 2009; Rochat, 2003; Steiner, 1996); though this may not be completely true (Kouider et al., 2013; Gopnik, 2010). This assumption is based only on the volume of the brain. Wherein the connections in the brain or neural correlates have to reach a minimum of $80 \%$ so that the brain can become fully conscious (Baars and Gage, 2010) and needs to be evaluated from all perspectives. For a long time, scientists believed that neuroplasticity stopped around adolescence and that new changes could not be formed after a specific time period (Pascual-Leone et al., 2005). But, latest evidence shows that neuroplasticity is an on-going process and never stops until death. As a result, new neural connections are formed at all times as part of one's learning process (Askenasy and Lehmann, 2013)

From birth, the child's brain already has about all of the neurons it will ever have and it doubles in size in the first year, and by age three it has reached 80 percent of its adult volume. During the prenatal period, the brain cells are already busy sending and receiving messages regarding touch, hearing and movement, with the other senses like taste, smell and sensitivity to light also being developed (Oates et al., 2012; DehaeneLambertz and Spelke, 2015; Shonkoff and Phillips 2000). At about three months, an infant's power of recognition seems to improve dramatically. This coincides with significant growth in the hippocampus and other limbic structures that are related to recognition memory (Uematsu et al., 2012). Language circuits in the frontal and temporal lobes become consolidated in the first year influenced strongly by the language and other external auditory inputs; which is all part of the growing neuroplasticity in an infant (Ullman, 2004).

According to some researchers, be it the readiness potential or consciousness, all of it emerges from the cortex of the brain. In this connection, several neuroscientific studies have been conducted to prove that the existence of consciousness lies in the brain, or rather to be more specific, the cortex of the brain. But, till date, this notion still remains inconclusive and is open for speculations (Crick and Koch, 1998; Dehaene and Naccache, 2001; Kurthen et al., 1998; Desmurget, 2013; Farisco et al., 2018; Koch et al., 2016). But then again, here, we have a case of a boy without the cortex and who willfully grew his cortex after his birth - as a choice (internal), and 
with the support of his parents and loved ones (external).

External psychological influence leading to recovery can be observed in patients with major changes to the brain such as strokes, injuries or conditions such as dementia that clearly affect and impair their functioning (Chriki et al., 2006; Letswaart et al., 2011; Bender and Constance, 2005; Clare et al., 2012; Schiff, 2010; Samuel, 2008; Morse and Garner, 2018). Minor neural changes such as those caused in drugs and alcohol addicted patients have been reversed by external psychological influence through rehabilitation courses in meditation and mindfulness (Winkelman, 2001; Garland et al., 2014; Garland and Howard, 2018). It has also been observed that mindfulness-based OCD treatment has brought about substantial changes in the neural patterns of these patients proving the existence of an external source of power (Külz et al., 2014; Gasnier et al., 2017; Goodwin et al., 2018). We know so much about the functioning of a normal healthy brain; as to how it manifests and develops with age and activities, but what if the brain or some regions of the brain are obliterated due to an illness or an injury. Can these regions re-grow and become fully functional? If such a stance is possible, what drives this phenomenon?

As for now, neuroscience has a limited understanding of neurogenesis. Neurogenesis is a process where new neurons develop, with its finding limited only to the hippocampus (until recently). This is the brain region responsible for learning information, storing long-term memories, and regulating emotions (Deng et al., 2010; Gage and Van Praag, 2002). Earlier this year, Queensland Brain Institute (QBI) made the world's first discovery that newadult brain cells are also produced in the amygdala, a region of the brain important for processing fear and emotional memories (Jhaveri et al., 2018). In brain damage patients, there is definitely a possibility of other regions of the brain taking over lost functions resulting in a partial recovery ( $\mathrm{Su}$ et al., 2016; Nudo, 2013) but growing a full brain all over again seems impossible. Many neuroscientists are attempting to grow fully formed brains in the lab by triggering skin cells to behave as pluripotent cells to form neural cells (Mason and Price, 2015). Neuroscience is definitely advancing towards understanding neurogenesis, but the present case offers something beyond imagination. The boy who lost $98 \%$ of his brain due to a destructive cyst at birth could grow it back once again to $80 \%$ in three years. The possibility of which we have interpreted in terms of his strong will to survive, which resulted in the choice and power to regrow. The will to re-grow his brain seemed to have emerged from a probabilistic source well known in quantum mechanics, which we assume, should be the basis from where everything comes.

A number of researchers are seeking support from neuro-quantum mechanics or quantum brain dynamics in order to understand the working of the epiphenomenal concepts such as consciousness, free will and the mind (Tarlaci, 2010; Penrose and Hameroff, 2011; Koch and Hepp, 2006; Penrose, 2018; Hameroff, 2013; Hameroff and Penrose, 2014; Jibu and Yasue, 1997; Van den Noort and Bosch, 2016). According to them, the qualitative aspects such as consciousness and free will acts on and acts to create out of an endless universe of predetermined possibilities (Schwartz et al., 2005; Hameroff, 2012). Choice, therefore also seems to be originating from the same source, and in order to understand it, we need to look deeper into the realms of the farfetched interpretations of quantum mechanics; within the brain as well as outside the brain. Although the physics and dynamics of choice can be reduced to a mere physical activity or neuronal firings in the brain, its origination within the neurons needs to be supported by the will to exhibit the choice (which may result from the most fundamental probabilistic state). We would like to present the following miraculous case before neuroscience to open up a debate over theories supporting the idea that brain is the seat of consciousness. From our understanding, it seems that, though the brain appears to be a crucial center regulating and mapping different functions, it may not be the only organ whose activity alone results in the emergence of consciousness.

\section{Noah's Will and his Choice to Survive}

Exceptions are not always the proof of the old rule; they can also be the harbinger of a new one. (Ebner-Eschenbach, 1994).

Excerpts for the case were taken from personal chats with Noah's mother Michelle Wall and father Rob Wall. Additional information was gathered from videos posted by the family over various online platforms 1,2,3, and verified later with his parents.

\footnotetext{
${ }^{1}$ https://www.hugsfornoah.co.uk/

${ }^{2}$ https://www.youtube.com/user/TheShellybobbins
} 
Noah's parents Rob and Michelle were told by their doctors during a routine scan that the chance of their boy surviving was impossible after he was diagnosed with spina bifida while still in the womb. At the same time, Noah was also diagnosed with hydrocephalus caused due to a porencephalic destructive cyst that left only $2 \%$ of his brain intact in his skull. As per the doctor's procedures, they considered not to resuscitate him in case he did not breathe on his own at birth. Noah's parents decided to give birth to him against the doctor's suggestion to abort him. In fact, the doctors had informed them that Noah would be born with severe mental and physical disabilities in case he survives. At birth, Noah let out an affirming scream like a normal child and his regular breathing puzzled the doctors, as he was breathing in the absence of the part of the brain that controls breathing. Immediately after he was born, Noah had to go through a rigorous 5-hour operation to close his spina bifida, which was a success. The doctors fitted him with a shunt to reduce the pressure in his brain by draining off the excess fluid accumulated in his skull. In no time Noah's fluid picked up an infection and the shunt had to be replaced, after which the doctors began to notice a significant change in his behavior which has been progressing as that of a normal child till date. As per Noah's neurosurgeon, his brain at 3 months of age should have been completely formed as shown in Fig 1 and 2. But due to the hydrocephalus condition, the skull was filled with cerebrospinal fluid (CSF) pushing the remaining $2 \%$ of the brain to the inner side of the skull, as observed in Fig 1 and 2.

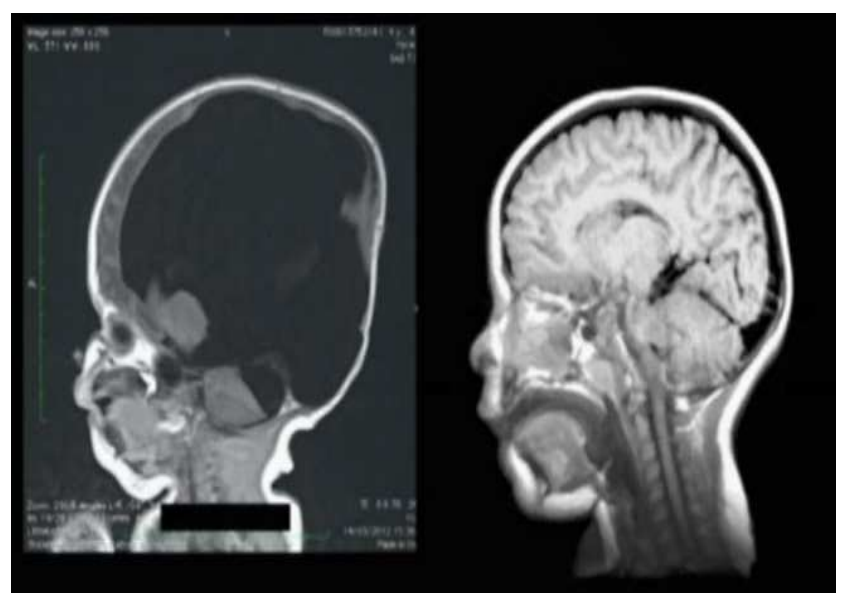

Figure 1. (Side view). MRI scans of Noah's brain at 3 months (left) in comparison to a normal brain of a 3-month-old child (right) Photo Credit: Noah's Father Rob Wall and Mother Michelle Wall

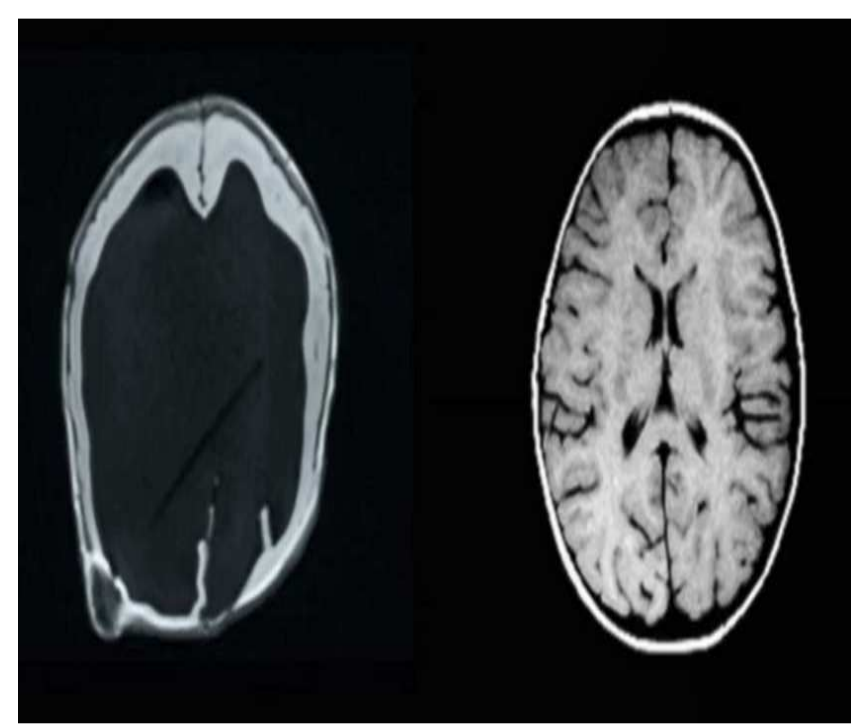

Figure 2. (Top View). MRI scans of Noah's brain at 3 months (left) in comparison to a normal brain of a child at 3 months (right)

Photo Credit: Noah's Father Rob Wall and Mother Michelle Wall

As discussed earlier, in neuroscience, the brain cortex is considered as the seat of consciousness. Accordingly, the emergence of free will and readiness potential are known to arise in the cerebral cortex (Panagiotaropoulos et al., 2012). But in the present case, the cerebral cortex was missing from Noah's brain, as can be seen in Fig 3. However, the brain scans did show the presence of the midbrain and brain stem, but the cortex was completely absent. In the absence of a cerebral cortex, the neuroscientific view of consciousness, free will and choice are highly challenged. Neuroscientists claim that the cerebral cortex in newborns are non-functional, as they possess the embryonic system of 'cerebral cortex,' which is not yet functioning, because it is still immature. Babies are therefore considered 'brainstem beings' (Dubuc, 2009), which may have been the case with Noah. Which means that Noah's brainstem triggered the growth of his brain, which began demonstrating several cognitive functions associated with his upper body, as compared to the severely impaired paralyzed lower body functions (due to the spina bifida). Even in considering the brain stem as the initiator, in this case, the question still remains unanswered as to what is it that triggered the brain stem to make a choice for the brain to re-grow?

\footnotetext{
3https://vimeo.com/202356061
} 


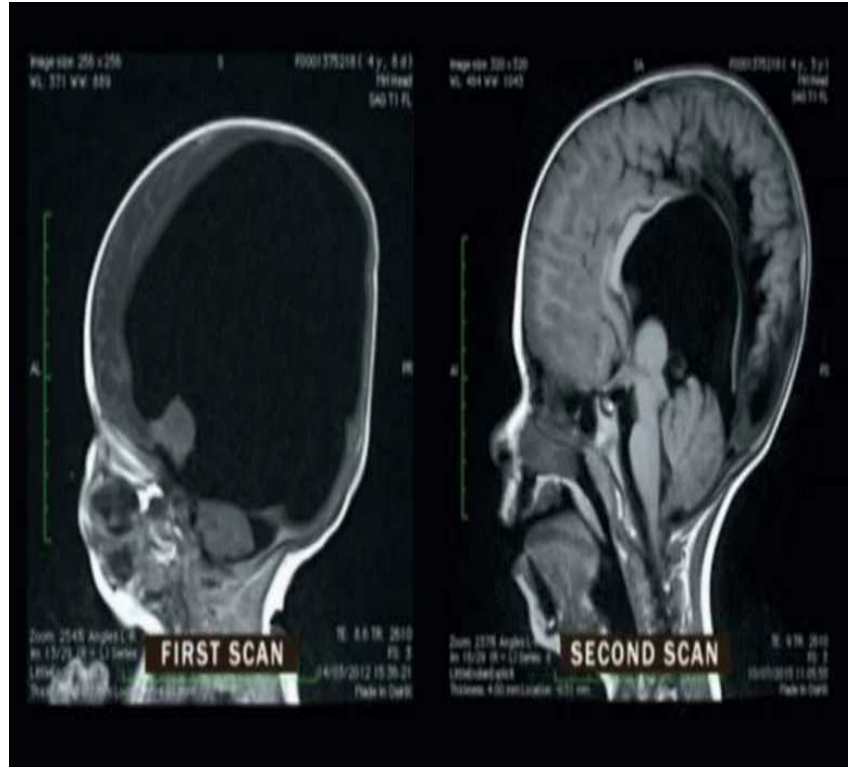

Figure 3. MRI scans of Noah's brain at 3 months (First Scan) and 2 years (Second Scan)

Photo Credit: Noah's Father Rob Wall and Mother Michelle Wall

Noah's level of awareness was very high since his birth and till date is growing at a rate as that of a normal child. Noah's Consultant Neurosurgeon says: 'Noah teaches the medical profession that you can't ever know, that it doesn't matter how many statistics you throw at something, you can't predict.' Noah is a strongwilled child and so are his parents and the result is evident from the ability to re-grow his brain to full potential. It is true that at this age it is difficult for the parents to convince Noah, but they have been compassionate and loving to the child, and in this manner assured that the will to make a choice exhibited by Noah should not be broken. From an external source, Noah's will must be encouraged and steered with love for him to progress further. Noah has discovered that self-control, carefulness, a sense of responsibility and strength of decision are virtues in themselves and can support him for the rest of his life.

Noah's case has astounded the whole of the neuroscience community with his ability to overcome all obstacles whether physically, psychologically or emotionally. His growing brain is a sign of neuroplasticity and the development of newer connections which are making his brain work wonders for him. A rigorous regime of input and stimulation by family members seems to be supporting the development of new pathways in Noah's brain which can be observed in the cognitive build-up. Noah is now 6 years old and his development has been like that of a normal child with the brain continuously growing to its full capacity and establishing its new connections. The reason for his miraculous recovery is definitely because of his willpower that made a choice to survive and the external support and motivation (as a sensory stimulation provided by his family, doctors and caregivers). Surprisingly, infants with hydrocephalus are termed 'decorticate' or completely without a cortex, where it is considered fatal within the neuroscientific community (Brown et al., 1973). It is generally accepted that children in such a state are mentally retarded and would be considered being "vegetative" and not being consciously aware (MSTF, 1994, RCP, 2003). In the present case, the narrow-mindedness of the neuroscientific community does not take choice and will into existence, because for them consciousness is absent in this case. But Noah's case disproves them as it is clearly evident that this boy's willpower to survive is what brought about a significant $80 \%$ growth of his brain.

Surprisingly, born with only $2 \%$ of his brain and paralyzed below his waist, Noah's development over the years has been like that of a normal child. When his brain scans were performed at the age of 2 , it was found that the $2 \%$ brain had now grown to an $80 \%$ and is still growing to a state of full recovery. Though he is paralyzed below the waist because of his spina bifida that impacted some of his cognitive abilities, his growing brain does not restrict him from doing any kind of activity. Besides his walking disability, he is cognitively very strong and uses his arms to his fullest which is clearly evident in the videos that have been posted by his parents. Noah's case demonstrates his willpower that made a choice to survive, which resulted in the growth of his brain which situates an example of understanding free will and choice from a neuro-quantum mechanics interpretation. Where besides our internal state there is also an external state which contributes to its emergence. External choices are sensory stimulations associated with love, care, emotions, trust, empathy, etc. that can have a direct impact on the emergence of choice. But, how the external state and internal state are connected within the void is yet to be determined. Willpower, choice and consciousness are correlated but are definitely discrete fields and therefore should not be wholly directed to the brain and its functional systems. Quantum mechanics can provide us a better understanding of these concepts from a probabilistic approach rather than a deterministic one. 


\section{Quantum Interpretation of Will and Choice}

Quantum mechanics is the first theoretical paradigm that accounts for all kinds of aggregates (such as atoms) from their first principles, which are actually encountered in nature (Schrödinger, 2012). Heisenberg's uncertainty principle (Heisenberg, 1927) and Schrödinger's cat thought experiments (Schrödinger, 1935) changed the deterministic approach of Newtonian and Einsteinian physics to a physics of uncertainty. Accordingly, the location of a particle cannot be determined for it may be in many places simultaneously, hence makes it fundamentally, intrinsically and insurmountably uncertain. The wave function collapse first demonstrated by Sudarsky and his collaborators in actuality is linked to the emergence of structures in the universe (León et al., 2014), and this can also support the possibility of epiphenomenal aspects such as consciousness, choice and free will (Okon and Sebastián, 2018; Penrose, 1989; Hameroff and Penrose, 2014; Hagan et al., 2001; Hameroff, 2012). Consciousness is a product of a fundamental property (Chalmers, 2002) which lies unknown, while free will is an emerging property of consciousness (Van Heuveln, 2000) that can give rise to a choice. At a quantum level, everything is probabilistic but the moment it becomes deterministic is when the manifestation of an event actually occurs (Pereira and Reddy, 2017). Quantum physics is the supporting pillar for all the physical manifestations that we observe and perceive. The universe as it is perceived currently looks purely mechanical and mathematical, because of which it seems orderly from a deterministic approach (Reddy and Pereira, 2016). When we look at this concept from a quantum perspective, we maybe well-defined beings, but our thoughts are still emergent from a probabilistic state; a state of nothingness or state of thoughtlessness (that can also be taken as the quantum void of subjectivity), which by no means we can perceive (Paraoanu, 2014; Pereira and Reddy, 2017).

One cannot search for something that one does not know about, because one already knows what it is, but cannot perceive it and so the frustration (U. G. Krishnamurthy, Newland 1998).

Quantum uncertainty means that even the nothing of free space has a small chance of containing something, in the form of energy. Energy, being the most fundamental unit that lies in the external, by some mechanism influences the internal; though we can see its working and manifestations, we cannot know its origin. It is just like how you cannot separate the tide from the sea. This is where our subjectivity originates, from this sea of nothingness to manifest into forms and deeds which we live with and experience (Pereira and Reddy, 2016). Free will is, therefore, a quantum uncertainty which emerges with the collapse of the wave function, and which is a complex psychological sensation that cannot be understood but can definitely be felt when an event occurs (which we perceive as our choice). Von Neumann-Wigner interpretation was the first attempt to introduce the mathematics of quantum mechanics that allows the collapse of the wave function with relation to the subjective experience of the observer (Von Neumann and Beyer, 1955; Wigner and Margenau, 1967); though many challenged the idea (Brown, 2017). We must understand that it is not the actual quantum mechanical collapse of the wave function which is relevant to our present case, but the interpretation which is probabilistic that may play an important role in understanding free will and choice.

Even if we had the perfect knowledge of all the neural connections in the brain, based on the quantum uncertainty principle, one cannot predict what the brain will do next. Free will supports the choice to manifest from a probabilistic state to a deterministic state. It is like moving from an unconscious state to a conscious state, where the will at play exerts a thought that can be linked to the readiness potential that makes these choices much before we can acknowledge it consciously. But, according to Ben Libet, if a decision isn't consciously made, then it isn't freely made and any action driven by such unconscious decision is not a free action; which may appear so from a superficial position. To support the non-existence of free will he claimed that, free will cannot initiate a choice or action but it can veto an intention to perform an action, wherein once you become conscious it can exert an action (Libet, 1993, 1999). We expect the choice to be uniform throughout our lives, but we need to understand that free will exists only when it is needed most by the body. Noah's case clearly demonstrates this, wherein it was his will that drew his choice (as the event of the collapsing of the wave function) that resulted in an action to make a change to his body which was supported as a conscious decision. This action was enriched externally by the influence of love, compassion and determination exhibited by his friends and family over him as mentioned by his neurosurgeon. Noah's family provides so much 
input from the external in the form of learning, which in neuroscience is termed as sensory stimulation or brain training and this has led him to become cognitively stronger.

Recoveries due to external support (love, compassion, caring, motivation, etc.) have been observed in stroke victims with partial paralysis or Hemiplegia, wherein the constant interaction of the patients with their caregivers results in a miraculous recovery to a normal state. Here there is a buildup of free will which makes a choice because of an external force which should be accepted. There are also cases where individuals without constant interaction with the caregiver and so, exhibit no willpower to come out of this state and remain paralyzed for the rest of their life (Popovich et al., 2007; Langhammer, 2007; Gallacher et al., 2018; De La Mare, 2005). For humanistic psychologists such as Maslow (1943) and Rogers (1951), freedom is not only possible but also necessary if we are to become fully functional human beings. Conscious reflection of the will exhibited as choices on our own behavior is seen as the best way of achieving goals and learning from mistakes (Baumeister et al., 2011). Child psychologists believe that the will to make a choice begins at a much earlier age in children even before they can talk. Motor development in the first year demonstrates how children are able to control their bodies and make them move through the world (Hohmann and Weikart, 1995; David et al., 2003). External support from parents, caregivers, etc., such as motivation, appreciation and love make them exhibit their choices and achieve results at a faster rate. The interpretation of quantum mechanics from a choice perspective clearly fits the explanation of how thought as a will to make a choice emerges and how it can be influenced by external and internal factors. It is for sure the resultant of a fundamental unit manifesting itself to a state of determinism where it gets perceived as real.

\section{Conclusions}

I have free will, but not of my own choice. I have never freely chosen to have free will. I have to have free will, whether I like it or not! (Smullyan, 1977). Mental effort within the contemporary physical theory, by means of effects of willful focus of attention, results in major changes in the brain which are not automatic reflexes of the brain mechanism alone. Traditionally, neuroscientists tried to define consciousness as the product of brain activity; where the brain is the physical substance and consciousness the resultant of the neuronal firings. According to them, consciousness is merely an epiphenomenon of the brain and can only be understood in terms of neurology. But growing evidence shows that consciousness goes far beyond the physical workings of the brain. Free will and choice are a phenomenon in its own right, with its own features, and it cannot be reduced by neuroscience. Neurological terms are often used to describe psychological phenomena as if they are the same thing, but consciousness, choice and free will are not just products of brain activity. If it were, it would be impossible for changes in psychological functioning to bring about changes in the brain, in the same way that it would be impossible for changes in the images on a computer screen to bring about changes to the circuitry of a computer.

Free will and choice is neither a myth nor a metaphor, they exist and for sure exerts a physical force to bring about a change when needed. The inter-determinism of quantum mechanics speaks of our ability to not know the outcome until an observer makes a measurement and it is not those random events that are causing everything. Outcomes are not determined by prior or random events, but by consciousness that gives rise to these outcomes. Hence particles are not causing our actions but it is we who are affecting the outcome of our reality. Free will is the ability for the mind to choose between possible outcomes. Noah's case out rightly challenges the neuroscientific research which currently stills lingers on some of the traditional neurophysiologic theories that free will and choice do prior exist and that consciousness requires neocortical functioning. For where exactly these probabilistic features reside in the brain is not yet known and will never be known, as the brain through conscious is not the only organ that is conscious. For free will, choice and consciousness are highly probabilistic states and their mechanism requires a deeper understanding from a neuro-quantum perspective.

\section{Acknowledgments}

A big thank you to Noah Wall without whom this manuscript would not be possible and who has proved to us that the will and its power exist and it can surely work miracles. We would also like to thank Rob and Michelle Wall for providing us the videos and documents from Noah's case papers and for being patient with our never-ending questions. We wish Noah all the best for his future 
and to keep astounding us with his feats. To know more about Noah's activities and for regular updates on him, we recommend visiting https://www.hugsfornoah.co.uk/.

\section{References}

Askenasy JJ, Lehmann J. Consciousness, brain, neuroplasticity. Frontiers in Psychology 2013; 4: 412.

Baars BJ, Gage NM. Cognition, brain, and consciousness: Introduction to cognitive neuroscience. Academic Press, 2010.

Baker KS, Mattingley JB, Chambers CD, Cunnington R. Attention and the readiness for action. Neuropsychologia 2011; 49(12): 3303-13.

Baumeister RF, Masicampo EJ, Vohs KD. Do conscious thoughts cause behavior?. Annual Review of Psychology 2011; 62: 331-61.

Bender M, Constance G, Williams J, Harris B. Wadebridge Memory Bank: a psychoeducation group. Journal of Dementia Care 2005; 13(1): 28-30.

Beresford B, Sloper P. Understanding the dynamics of decision-making and choice: A scoping study of key psychological theories to inform the design and analysis of the Panel Study. York: Social Policy Research Unit, University of York, 2008.

Brown HR. The reality of the wavefunction: old arguments and new. http://philsci-archive.pitt.edu/12978/1/SanSebastian\%202.pdf. Accessed date: April 22, 2018.

Brown JK, Ingram TT, Seshia SS. Patterns of decerebration in infants and children: defects in homeostasis and sequelae. Journal of Neurology, Neurosurgery \& Psychiatry 1973; 36(3): 431-44.

Carl R. Client-Centered Therapy: Its Current Practice, Implications and Theory. London: Constable. ISBN 184119-840-4. 1951.

Chalmers DJ. Consciousness and its place in nature. In Philosophy of Mind: Classical and Contemporary Readings. Oxford UK: Oxford University Press, 2002.

Chriki LS, Bullain SS, Stern TA. The recognition and management of psychological reactions to stroke: A case discussion. Prim Care Companion Journal of Clinical Psychiatry 2006; 8(4): 234-40.

Clare L, Nelis SM, Martyr A, Roberts J, Whitaker CJ, Markova IS, Roth I, Woods RT, Morris RG. The influence of psychological, social and contextual factors on the expression and measurement of awareness in early-stage dementia: Testing a biopsychosocial model. International Journal of Geriatric Psychiatry 2012; 27(2): 167-77.

Crick F, Koch C. Consciousness and neuroscience. Cerebral Cortex 1998; 8(2): 97-107.

Coutlee CG, Huettel SA. The Functional Neuroanatomy of Decision Making: Prefrontal Control of Thought and Action. Brain Research 2012; 1428: 3-12.

David T, Goouch K, Powell S, Abbott L. Birth to three matters: A review of the literature. London: DfES, 2003.

de la Mare B. The experience of stroke and the life of the Spirit. Medical Humanities 2005; 31(2): 105-08.

Deecke L. There Are Conscious and Unconscious Agendas in the Brain and Both Are Important-Our Will Can Be Conscious as Well as Unconscious. Brain Science 2012; 2(3): 405-20.
Dehaene S, Naccache L. Towards a cognitive neuroscience of consciousness: basic evidence and a workspace framework. Cognition 2001; 79(1-2): 1-37.

Dehaene-Lambertz G, Spelke ES. The infancy of the human brain. Neuron 2015; 88(1): 93-109.

Deng W, Aimone JB, Gage FH. New neurons and new memories: How does adult hippocampal neurogenesis affect learning and memory? Nature Reviews Neuroscience 2010; 11(5): 339-50.

Desmurget M. Searching for the neural correlates of conscious intention. Journal of Cognitive Neuroscience 2013; 25(6): 830-33.

Domenech P and Koechlin E. Executive control and decisionmaking in the prefrontal cortex. Current Opinion in Behavioral Sciences 2015; (1): 101-06.

Dubuc B. The Brain from top to bottom. Canadian Institute of Health Research/ Canadian Institute of Neurosciences, Mental Health and Addiction. 2009. https://www.babycentre.co.uk/a6621/your-babys-brainthe-brain stem\#ixzz5FvVDp9lV. Accessed date: April 23, 2018.

Ebner-Eschenbach MV. Aphorisms. Ariadne Press (CA), 1994.

Farisco M, Kotaleski JH, Evers K. Large-scale brain simulation and disorders of consciousness. Mapping Technical and Conceptual Issues. Frontiers in Psychology 2018; 9: 585.

Finkelstein DH. On the distinction between conscious and unconscious mind. American Philosophical Quarterly 1999; 36 (2): 79 - 99.

Gage FH, Van Praag H. Neurogenisis in adult brain. Neuropsychopharmacology: The Fifth Generation of Progress. Edited by Kenneth L. Davis, Dennis Charney, Joseph T. Coyle, and Charles Nemeroff. American College of Neuropsychopharmacology. LWW; 5 th ed. edition.

Gallacher KI, May CR, Langhorne P, Mair FS. A conceptual model of treatment burden and patient capacity in stroke. BMC Family Practice 2018; 19(1): 9.

Garland E, Froeliger B, Howard M. Mindfulness training targets neurocognitive mechanisms of addiction at the attention-appraisal-emotion interface. Frontiers in Psychiatry 2014; 4: 173.

Garland EL, Howard MO. Mindfulness-based treatment of addiction: current state of the field and envisioning the next wave of research. Addiction Science \& Clinical Practice 2018; 13(1): 14.

Gasnier M, Pelissolo A, Bondolfi G, Pelissolo S, Tomba M, Mallet L, N'diaye K. Mindfulness-based interventions in obsessive-compulsive disorder: Mechanisms of action and presentation of a pilot study. Encephale 2017; 43(6): 59499.

Glasser W. The choice theory: A new psychology of personal freedom (Kim, IJ \& Woo, AR Trans). Seoul: Korea Counseling Center, 1998.

Goodwin GM, Holmes EA, Andersson E, Browning M, Jones A, Lass-Hennemann J, NTMånsson K, Moessnang C, Salemink E, Sanchez A, Zutphen L, Visser RM. From neuroscience to evidence based psychological treatments - The promise and the challenge, ECNP March 2016, Nice, France. European Neuropsychopharmacology 2018; 28 (2): 31733.

Gopnik A. 2010. How babies think. Scientific American 2010; 76-80. alisongopnik.com/Papers_Alison/sciamGopnik.pdf. Accessed date: May 10, 2018.

Hagan S, Hameroff SR, Tuszyński JA. Quantum computation in brain microtubules: Decoherence and biological feasibility. Physical Review E 2002; 65(6): 061901. 
Hameroff S. Consciousness, the brain, and spacetime geometry. Annals of the New York Academy of Sciences 2001; 929(1): 74-104.

Hameroff S. How quantum brain biology can rescue conscious free will. Frontiers in Integrative Neuroscience 2012; 6: 93.

Hameroff S, Penrose R. Consciousness in the universe: A review of the 'Orch OR'theory. Physics of Life Reviews 2014; 11(1): 39-78.

Heisenberg W. Über den anschaulichen Inhalt der quantentheoretischen Kinematik und Mechanik. Zeitschrift für Physik 1927; 43 (3-4): 172-98.

Hohmann M, Weikart DP. Educating young children: Active learning practices for preschool and child care programs from educating young children, a curriculum guide from High/Scope Educational Research Foundation USA, 1995: 13-41.

Holton R. The act of choice. Philosophers Imprint 2006; 6 (3). www.philosophersimprint.org/006003/. Accessed date: April 10, 2018.

HugsForNoah BBC World Service Interview. 2016. https://audioboom.com/posts/5194167-hugsfornoahbbc-world-service-interview?t=0. Accessed date: May 3, 2018.

Hugs for Noah: https://www.hugsfornoah.co.uk/. Accessed date: May 10, 2018.

Ietswaart $\mathrm{M}$, Johnston $\mathrm{M}$, Dijkerman $\mathrm{HC}$, Joice $\mathrm{S}$, Scott $\mathrm{CL}$, MacWalter RS, Hamilton SJC. Mental practice with motor imagery in stroke recovery: randomized controlled trial of efficacy. Brain 2011; 134(5): 1373-86.

Jhaveri DJ, Tedoldi A, Hunt S, Sullivan R, Watts NR, Power JM, Bartlett PF, Sah P. Evidence for newly generated interneurons in the basolateral amygdala of adult mice. Molecular Psychiatry 2018; 23(3): 521-32.

Jibu M, Yasue K. What is mind?- Quantum field theory of evanescent photons in brain as quantum theory of consciousness. INF 1997; 21(3): 471-90.

Klemm WR. Free will debates: Simple experiments are not so simple. Advances in Cognitive Psychology 2010; 6: 47-65.

Koch C, Hepp K. Quantum mechanics in the brain. Nature 2006; 440 (7084): 611.

Koch C, Massimini M, Boly M, Tononi G. Neural correlates of consciousness: progress and problems. Nature Reviews Neuroscience 2016; 17(5): 307-21.

Kornhuber HH, Deecke L. The will and its brain - an appraisal of reasoned free will. Lanham: University Press of America, 2012.

Kouider S, Stahlhut C, Gelskov SV, Barbosa LS, Dutat M, de Gardelle V, Christophe A, Dehaene S, Dehaene-Lambertz G. A neural marker of perceptual consciousness in infants. Science 2013; 340(6130): 376-80.

Külz AK, Landmann S, Cludius B, Hottenrott B, Rose N, Heidenreich T, Hertenstein E, Voderholzer U, Moritz S. Mindfulness-based cognitive therapy in obsessivecompulsive disorder: protocol of a randomized controlled trial. BMC Psychiatry 2014; 14: 314.

Kurthen M, Grunwald T, Elger CE. Will there be a neuroscientific theory of consciousness? Trends in Cognitive Science 1998; 2(6): 229-34.

Lagercrantz H, Changeux JP. The emergence of human consciousness: from fetal to neonatal life. Pediatric Research 2009; 65(3): 255-60.

Langhammer B. Physiotherapy after stroke - a lifetime endeavour. Dissertation Faculty of Medicine, University of Oslo, Norway, 2007.
Lattari E, Arias-Carrión O, Monteiro-Junior RS, Portugal EM, Paes F, Menéndez-González $\mathrm{M}$, Silva AC, Nardi AE, Machado S. Implications of movement-related cortical potential for understanding neural adaptations in muscle strength tasks. International Archives of Medicine 2014; $7(1): 9$.

Lavazza A. Free will and neuroscience: From explaining freedom away to new ways of operationalizing and measuring it. Frontiers in Human Neuroscience 2016; 10: 262.

León G, Landau SJ, Piccirilli MP. Quantum collapse as a source of the seeds of cosmic structure during the radiation era. Physical Review D 2014; 90(8): 083525.

Libet B. Do we have free will?. Journal of Consciousness Studies 1999; 6 (8-9): 47-57.

Libet B. Unconscious cerebral initiative and the role of conscious will in voluntary action. Behavioral and brain sciences 1985; 8(4): 529-39.

Lichtenberg GC. Aphorisms. Notebook J, 1789: 249.

Maslow AH. A theory of human motivation. Psychological Review 1943; 50 (4): 370-96.

Mason JO, Price DJ. Building brains in a dish: prospects for growing cerebral organoids from stem cells. Neuroscience 2016; 334: 105-18.

Morris SG. The impact of neuroscience on the free will debate. Florida Philosophical Review 2009; 9(2): 56-78.

Morse AM, Garner DR. Traumatic brain injury, sleep disorders, and psychiatric disorders: an underrecognized relationship. Medical Sciences 2018; 6(1): 15.

Multi-Society Task Force on PVS. Medical aspects of the persistent vegetative state - first of two parts. New England Journal of Medicine 1994; 330(21): 1499-508.

Newland T. Mind is a Myth: Disquieting conversations with the man called U.G. Dinesh Publications, 1998.

Nudo RJ. Recovery after brain injury: mechanisms and principles. Frontiers in Human Neuroscience 2013; 7: 887.

Oates J, Karmiloff-Smith A, Johnson MH. Developing brains. Child and Youth Studies Group, The Open University, UK, 2012.

Okon E, Sebastián MA. A Consciousness-based quantum objective collapse model. 2018. http://philsciarchive.pitt.edu/14299/1/ConCSL16.pdf. Accessed date: April 23, 2018.

Panagiotaropoulos TI, Deco G, Vishal Kapoor V, Logothetis NK. Neuronal discharges and gamma oscillations explicitly reflect visual consciousness in the lateral prefrontal cortex. Neuron 2012; 74 (5): 924-35.

Paraoanu GS. The quantum vacuum. 2014. https://arxiv.org/pdf/1402.1087.pdf. Accessed date: April 23, 2018.

Pascual-Leone A, Amedi A, Fregni F, Merabet LB. "The plastic human brain cortex". Annual Review of Neuroscience 2005; 28: 377-401.

Penrose R. Edge Conversation Chapter 14: Consciousness Involves Noncomputable Ingredients 1996. https://www.edge.org/conversation/roger_penrosechapter-14-consciousness-involves-noncomputableingredients. Accessed date: April 11, 2018.

Penrose R. The Emperor's New Mind, Oxford: Oxford University Press, 1989.

Penrose R, Hameroff S. Consciousness in the universe: Neuroscience, quantum space-time geometry and orch or theory. Journal of Cosmology 2011: 14. http://www.neurohumanitiestudies.eu/archivio/penrose _consciousness.pdf. Accessed date: January 26, 2018. 
Pereira C. Consciousness is Quantum Computed Beyond the Limits of the Brain: A Perspective Conceived from Cases Studied for Hydranencephaly. NeuroQuantology 2016; 14 (3): 613-18.

Pereira C, Reddy JSK. The manifestation of consciousness: beyond \& within from fundamental to ubiquity. Journal of Consciousness Exploration \& Research 2017; 8 (1):51-55.

Pereira C and Reddy JSK. Science, subjectivity \& reality. Journal of Consciousness Exploration and Research 2016; 7(4): 333-36.

Peters MA, Kentridge RW, Phillips I, Block N. Does unconscious perception really exist? Continuing the ASSC20 debate. Neuroscience of Consciousness 2017; $3(1)$.

Popovich JM, Fox PG, Bandagi R. Coping with stroke: Psychological and social dimensions in U.S. patients. The International Journal of Psychiatric Nursing Research 2007; 12(3): $1474-87$.

Reddy JSK, Pereira C. An Essay on 'Fracto-Resonant' Nature of Life. NeuroQuantology 2016; 14(4): 764-69.

Rochat P. Five levels of self-awareness as they unfold early in life. Consciousness and Cognition 2003; 12: 717-731.

Royal College of Physicians Working Group. The permanent vegetative state. Journal of the Royal College of Physicians of London 1996; 30: 119-21.

Samuel R. Cognitive rehabilitation for reversible and progressive brain injury. Indian Journal of Psychiatry 2008; 50(4): 282-84.

Schiff ND. Recovery of consciousness after brain injury: A mesocircuit hypothesis. Trends in Neuroscience 2010; 33(1): 1-9.

Schrödinger E. What is life?: With mind and matter and autobiographical sketches (Canto Classics). Cambridge: Cambridge University Press, 2012.

Schrödinger E. Die gegenwärtige Situation in der Quantenmechanik. Naturwissenschaften 1935; 23 (48): 807-12.

Schwartz JM, Stapp HP, Beauregard M. Quantum physics in neuroscience and psychology: a neurophysical model of mind-brain interaction. Philosophical Transactions of the Royal Society of London, Series B Biological Sciences 2005; 360(1458): 1309-27.

Shellybobbins: https://www.youtube.com/user/TheShellybobbins. Accessed date: May 10, 2018.

Shonkoff JP, Phillips DA. From neurons to neighborhoods : The science of early childhood development. National Academies Press USA, 2002.

Steiner R. The Child's changing consciousness: As the basis of pedagogical practice. New York: Anthroposophic Press, 1996.
Smullyan R. Is God a taoist?. Reissue edition, Harper One Publisher, 1977.

Strle T. Does consciousness cause behaviour? Implications for moral responsibility. Inštitut Jožef Štefan 2014; 84 -89. http://pefprints.pef.uni-lj.si/2539/. Accessed date: April 23, 2018.

Su YS, Veeravagu A, Grant G. Neuroplasticity after Traumatic Brain Injury. Translational Research in Traumatic Brain Injury, Laskowitz D, Grant G, editors. Boca Raton (FL): CRC Press/Taylor and Francis Group, USA, 2016.

Tarlaci S. Why we need quantum physics for cognitive neuroscience. NeuroQuantology 2010; 8 (1): 66-76.

Torregosa MB, Sada R, Perez I. Dealing with stroke: Perspectives from stroke survivors and stroke caregivers from an underserved Hispanic community. Nursing and Health Sciences 2018.

Tversky A, Kahneman D. The Framing of Decisions and the Psychology of Choice. Science 1981; 211 (4481): 453-58.

Uematsu A, Matsui M, Tanaka C, Takahashi T, Noguchi K, Suzuki M, Nishijo H. Developmental trajectories of amygdala and hippocampus from infancy to early adulthood in healthy individuals. PloS One 2012; 7(10): e46970.

Ullman MT. Contributions of memory circuits to language: The declarative/procedural model. Cognition 2004; 92: 231-70.

Van den Noort M, Lim S, Bosch P. On the need to unify neuroscience and physics. Neuroimmunology and Neuroinflammation 2016; 3: 271-73.

Van Heuveln B. Emergence and Consciousness: Explorations into the Philosophy of Mind via the Philosophy of Computation. Ph.D. Dissertation, Binghamton University. 2000.

http://www.oneonta.edu/faculty/vanheub/thesis.pdf. Accessed date: May 19, 2018.

Vimeo TV. https://vimeo.com/202356061. Accessed date: May 10, 2018.

Von Neumann J. Beyer RT. Mathematical Foundations of Quantum Mechanics. New Jersey: Princeton University Press, 1995.

Wigner E, Margenau H. Remarks on the mind body question, in symmetries and reflections, scientific essays. American Journal of Physics 1967; 35 (12): 1169-70.

Winkelman M. Alternative and traditional medicine approaches for substance abuse programs: A shamanic perspective. International Journal of Drug Policy 2001; 12: 337-51.

Zschorlich VR, Köhling R. How thoughts give rise to action conscious motor intention increases the excitability of target-specific motor circuits. PLoS One. 2013; 8(12): e83845. 